\title{
Regional adiposity, cardiorespiratory fitness, and left ventricular strain: an analysis from the Dallas Heart Study
}

\author{
Nitin Kondamudi ${ }^{1}$, Neela Thangada ${ }^{3}$, Kershaw V. Patel ${ }^{4}$, Colby Ayers ${ }^{2}$, Alvin Chandra' ${ }^{1}$ Jarret D. Berry ${ }^{1}$, \\ Ian J. Neeland ${ }^{5}$ and Ambarish Pandey ${ }^{1 *}$
}

\begin{abstract}
Background: Low cardiorespiratory fitness (CRF), high body mass index, and excess visceral adiposity are each associated with impairment in left ventricular (LV) peak circumferential strain $\left(E_{c c}\right)$, an intermediate phenotype that precedes the development of clinical heart failure (HF). However, the association of regional fat distribution and CRF with $\mathrm{E}_{c c}$ independent of each other and other potential confounders is not known.

Methods: Participants from the Dallas Heart Study Phase 2 who underwent dual energy X-ray absorptiometry assessment of regional fat distribution, CRF assessment by submaximal treadmill test, and $\mathrm{E}_{\mathrm{cc}}$ quantification by tissuetagged cardiovascular magnetic resonance were included in the analysis. The cross-sectional associations of measures of regional adiposity, namely visceral adipose tissue (VAT), subcutaneous adipose tissue (SAT), and lower-body fat (LBF) with $\mathrm{E}_{\mathrm{cC}}$ after adjustment for CRF and other potential confounders (independent variables) were assessed using multivariable linear regression analysis.

Results: The study included 1089 participants (55\% female, 39\% black). In the unadjusted analysis, higher VAT was associated with greater impairment in $\mathrm{E}_{\mathrm{cC}}$. After adjustment for baseline risk factors, CRF, parameters of LV structure and function, and other fat depots such as SAT and LBF, higher VAT remained associated with greater impairment in $E_{c c}(\beta: 0.19, P=0.002)$. SAT and LBF were not significantly associated with $E_{C C^{\prime}}$ however, $C R F$ remained associated with $\mathrm{E}_{c \mathrm{c}}$ in the fully adjusted model including all fat depots $(\beta:-0.15, \mathrm{P}<0.001)$.
\end{abstract}

Conclusions: VAT and CRF are each independently associated with impairment in $\mathrm{E}_{C \mathrm{C}}$ suggesting that higher VAT burden and low CRF mediate pathological cardiac remodeling through distinct mechanisms.

Keywords: Visceral fat, Lower-body fat, Subcutaneous fat, Left ventricular peak circumferential strain, Heart failure

\section{Introduction}

Excess adiposity, as measured by body mass index (BMI), is associated with impaired myocardial function and higher risk of heart failure (HF) [1-6]. However, BMI is an imperfect representation of total adiposity because it

\footnotetext{
*Correspondence: ambarish.pandey@outlook.edu

${ }^{1}$ Division of Cardiology, Department of Internal Medicine, University

of Texas Southwestern Medical Center, 5323 Harry Hines Blvd, Dallas, TX 75390-9047, USA

Full list of author information is available at the end of the article
}

does not capture differences in lean body mass and fat distribution. Besides BMI, differences in cardiorespiratory fitness (CRF) and regional fat depots contribute significantly to obesity related HF risk [7, 8]. Although the mechanisms by which CRF and regional fat depots mediate HF risk are not well established, prior studies have reported epidemiological associations between CRF, visceral adiposity (VAT), and abnormal cardiac remodeling patterns. VAT has been associated with higher left ventricular (LV) mass and lower LV end diastolic volume

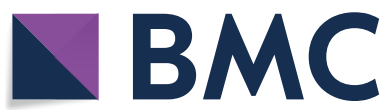

(c) The Author(s) 2021. Open Access This article is licensed under a Creative Commons Attribution 4.0 International License, which permits use, sharing, adaptation, distribution and reproduction in any medium or format, as long as you give appropriate credit to the original author(s) and the source, provide a link to the Creative Commons licence, and indicate if changes were made. The images or other third party material in this article are included in the article's Creative Commons licence, unless indicated otherwise in a credit line to the material. If material is not included in the article's Creative Commons licence and your intended use is not permitted by statutory regulation or exceeds the permitted use, you will need to obtain permission directly from the copyright holder. To view a copy of this licence, visit http://creativecommons.org/licenses/by/4.0/. The Creative Commons Public Domain Dedication waiver (http://creativeco mmons.org/publicdomain/zero/1.0/) applies to the data made available in this article, unless otherwise stated in a credit line to the data. 
(EDV) [5, 9], while CRF has been associated with higher LV filling pressures and diastolic dysfunction $[10,11]$. These cardiac remodeling patterns may reflect intermediate phenotypes in the progression from at-risk to clinical HF $[12,13]$.

LV peak systolic circumferential strain $\left(\mathrm{E}_{\mathrm{cc}}\right)$ is a sensitive marker of abnormal cardiac remodeling and is independently associated with risk of HF $[14,15]$. CRF and regional adiposity have each been associated with impairment in $\mathrm{E}_{\mathrm{cc}}$ independent of $\mathrm{BMI}[5,16]$. However, prior studies have not examined the association between regional fat distribution and subclinical myocardial dysfunction, independent of CRF, a potential confounder not accounted for in prior reports. Accordingly, we examined the associations between specific adipose tissue depots and $\mathrm{E}_{\mathrm{cc}}$ while adjusting for cardiovascular disease (CVD) risk factors, CRF, and LV parameters in a multi-ethnic, population-based cohort without known CVD. We hypothesized that higher amounts of VAT would be independently associated with greater subclinical impairment in $\mathrm{LV}$ contractility measured by $\mathrm{E}_{\mathrm{cc}}$.

\section{Methods \\ Study population}

The Dallas Heart Study (DHS) is a multiethnic, probability-based, population cohort study of Dallas County residents with deliberate oversampling of black individuals. Methods and study design of DHS have been described previously [17]. Individuals were enrolled in DHS-1 and underwent initial evaluation from 2000 to 2002. Between 2007 and 2009, participants were invited to DHS-2 to complete follow up testing at the University of Texas Southwestern Medical Center that included anthropometric measurements, laboratory tests, imaging studies, and fitness assessments. Patients who underwent fat depot measurements by dual-energy $x$-ray absorptiometry (DEXA) and cardiovascular magnetic resonance (CMR) were included in the present analysis. CMR was performed in 2106 participants in DHS-2, and 2037 of those studies included tagged CMR of sufficient quality for strain analysis. Participants with CVD, LV ejection fraction (LVEF) $<45 \%$, ß-blocker use, missing CRF data, missing DEXA data, or irregular/sub-optimal maximal predicted heart rate at target workload, were excluded. Heart rates $>100 \%$ or $<50 \%$ of maximal predicted heart rate at target workload were considered sub-optimal and individuals achieving those levels were also excluded. The final study sample included 1089 participants. All study participants provided written informed consent. The University of Texas Southwestern Medical Center institutional review board has approved the protocol for the DHS Phase II.

\section{Assessment of regional fat depots and lean body mass}

Total body fat and fat-free mass were measured using DEXA (Delphi W scanner, Hologic Inc, Bedford, Massachusetts, USA) as has been previously described [9]. DEXA derived total abdominal subcutaneous fat was subtracted from measured total abdominal fat to estimate VAT mass (total abdominal fat-total abdominal subcutaneous fat $=$ visceral adipose tissue) using APEX software version 13.4.2. Fat below oblique lines crossing the femoral necks to below the pubic symphysis is considered lower-body fat (LBF). Total lean body mass and appendicular lean mass (ALM) were measured by using a dual-beam absorption energy unit (Delphi W, Hologic, Inc.) bone densitometer in array mode. Body composition was quantified using Oasis software (Hologic, Inc.). ALM index was calculated by dividing ALM by height in meters squared.

\section{Assessment of cardiorespiratory fitness and physical activity levels}

A submaximal exercise treadmill test was used to estimate CRF as has been previously described $[16,18]$. In brief, oxygen uptake $\left(\mathrm{VO}_{2}\right)$ was estimated using Givoni's equation for metabolic energy cost. Maximal heart rate was estimated by subtracting the participant age from 220 , and then the \% maximal heart achieved was calculated. Using Hellerstein's formula, \% maximal heart rate was converted to estimated peak oxygen uptake $\left(\mathrm{VO}_{2 \max }\right)$ which was used to determine CRF. Moderate to vigorous physical activity (MVPA) levels were assessed among the study participants using an accelerometer (Actical, Philips Respironics, Bend, Oregon, USA) that was worn for 7 consecutive days on their non-dominant wrist. As reported previously, based on the accelerometer output (counts per min [CPM]), MVPA was defined as $>=1500$ CPM. Minutes spent above this threshold were averaged across all valid wear days to estimate the total daily duration of MVPA [19].

\section{Clinical covariates}

Assessment of demographic, clinical, and anthropometric characteristics in the DHS have been described previously [17]. Briefly, race was self-assigned according to US census categories. Smoking was defined as cigarette use within the previous 30 days and/or a lifetime history of having smoked $\geq 100$ cigarettes. Hypertension was defined as blood pressure $\geq 140 / 90 \mathrm{~mm} \mathrm{Hg}$ or taking antihypertensive medication(s). Diabetes mellitus was defined as having a fasting serum glucose $\geq 126 \mathrm{mg} /$ $\mathrm{dL}$, self-reporting a history of diabetes mellitus, or taking hypoglycemic medication. Hypercholesterolemia was defined as a calculated low-density lipoprotein 
cholesterol $\geq 160 \mathrm{mg} / \mathrm{dL}$ on a fasting sample, direct lowdensity lipoprotein cholesterol $\geq 160 \mathrm{mg} / \mathrm{dL}$ on a nonfasting sample, total cholesterol $\geq 240 \mathrm{mg} / \mathrm{dL}$, or use of statin medication. BMI was calculated using weight in kilograms divided by height in meters squared. Waist circumference was measured $1 \mathrm{~cm}$ superior to the iliac crest.

\section{Assessment of cardiac structure and function}

CMR was performed using a $3 \mathrm{~T}$ CMR system (Philips Healthcare, Best, The Netherlands). LV volume and LV mass were quantified using MASS software (Medis Medical Imaging Systems, Leiden, the Netherlands) on shortaxis breath-hold electrocardiogram (ECG) gated cine CMR images, as previously described [20]. Stroke volume was calculated as the difference in LV end-diastolic and end-systolic volumes (LVEDV, LVESV). LVEF was calculated using volumes [(LVEDV - LVESV) / LVEDV]*100. $\mathrm{E}_{\mathrm{cc}}$ was computed using the myocardial tissue tagging method [21, 22]. In brief, myocardium was tagged in the vertical and horizontal planes of the LV mid-ventricular short-axis slices. Strain was measured in six LV wall segments using harmonic phase imaging software offline (HARP, Diagnosoft Virtue 5.04; Diagnosoft, Palo Alto, California, USA). A global circumferential strain (GCS) graph was created with strain values at different LV wall segments and multiple time points throughout the cardiac cycle. The most negative point on the curve reflects $\mathrm{E}_{\mathrm{cc}}$. Less negative strain represents decreased $\mathrm{LV}$ wall shortening circumferentially and suggests impaired contractility, whereas more negative strain reflects more favorable contractility and better cardiac function.

\section{Statistical analysis}

The reproducibility in CMR measures $\mathrm{E}_{\mathrm{cc}}$ was assessed in a subset of randomly selected participants $(n=30)$ who had repeat blinded measurements of the Ecc parameter by the same operator on two separate occasions. The correlation between the paired measurements was assessed using a Pearson correlation test. The agreement between the paired measurements was assessed using the Bland Altman plot. Demographic and clinical characteristics of the study population were compared across race- and sex-adjusted quartiles of VAT using Wilcoxon rank-sum test for continuous variables and Chi-square test for categorical variables. The cross-sectional association between regional fat depots, CRF, and Ecc was assessed with separate multivariable adjusted linear regression models. The primary exposure variables were VAT, SAT, and LBF, and the outcome variable was $\mathrm{E}_{\mathrm{cc}}$. Separate models were constructed for VAT, SAT, and LBF exposure variables with sequential adjustment for the following confounders: Model 1-demographics (age, sex, race/ethnicity), traditional CVD risk factors (smoking status, fasting glucose, diabetes status, hypertension status, systolic blood pressure), and total lean body mass; Model 2-Model 1+CRF; and Model 3-Model 2+LV parameters (LV mass index and LVEF). A most adjusted Model 4 was additionally constructed which included all covariates in Model $3+$ the three regional adiposity parameters, VAT, SAT, and LBF, in the same model.

Standardized beta estimates were calculated for VAT, SAT, LBF, and CRF in each model, representing relative SD change in $E_{c c}$ per SD change in each respective independent variable while keeping other covariates fixed. Restricted cubic splines of each fat depot and $E_{c c}$ were constructed using Model 3. BMI stratified analysis [obese $\left(\mathrm{BMI}>30 \mathrm{~kg} / \mathrm{m}^{2}\right)$ vs. non obese] was also performed by evaluating the associations of VAT, SAT, and LBF with $\mathrm{E}_{\mathrm{cc}}$ among obese participants in the most adjusted model (Model 4). Sensitivity analysis was also performed by constructing additional models replacing total lean body mass with ALM (model 5), ALM index (model 6), and adding MVPA as another covariate to the most adjusted model 4 (model 7). A 2 -sided $P$ value $<0.05$ was considered statistically significant for all hypothesis testing. SAS (version 9.2, SAS Institute, Inc., Cary, North Carolina, USA) was used for statistical analyses.

\section{Results}

A total of 1089 participants (55\% female, 39\% black, median 48 years, BMI $29.1 \mathrm{~kg} / \mathrm{m}^{2}$ ) were studied. In a subset of $30 \mathrm{CMR}$ studies with repeated assessment of $\mathrm{E}_{\mathrm{cc}}$, we observed a moderate degree of correlation with a Pearson correlation coefficient of 0.542 . We also observed adequate agreement on the Bland Altman plot (mean difference: 1.23 , limits of agreement: -2.93 to 5.38 , see Additional file 1: Figure S1). Baseline characteristics of the study participants are compared across race- and sexadjusted quartiles of VAT (Table 1). In cross-sectional analysis, participants with higher amounts of VAT were more likely to be older, less fit, less active, and obese with higher prevalence of CVD risk factors, including hypertension, diabetes, and hypercholesterolemia. Participants with higher amounts of VAT were also more likely to have higher total lean body mass and ALM. Among imaging characteristics, participants with higher VAT were more likely to have greater impairment in $\mathrm{E}_{\mathrm{cc}}$, lower LVEDV, and higher LVEF. In contrast, LV stroke volume and LV mass index did not differ significantly across quartiles of VAT (Table 1).

\section{Association of regional fat depots with peak circumferential strain}

Multivariable adjusted cross-sectional associations of regional fat depots with $\mathrm{E}_{\mathrm{cc}}$ as observed using restricted 
Table 1 Study population characteristics across race- and gender-adjusted quartiles of visceral adiposity

\begin{tabular}{|c|c|c|c|c|c|}
\hline & Q1 & Q2 & Q3 & Q4 & $\begin{array}{l}P \\
\text { value }\end{array}$ \\
\hline N & 268 & 274 & 276 & 271 & - \\
\hline Visceral adipose tissue, kg & $1.1(0.8,1.4)$ & $1.7(1.5,2.5)$ & $2.4(2.0,3.3)$ & $3.4(2.8,4.3)$ & - \\
\hline \multicolumn{6}{|l|}{ Demographics } \\
\hline Age, years & $45.0(40.0,53.5)$ & $48.0(41.0,55.0)$ & $51.0(44.0,58.0)$ & $53.0(46.0,60.0)$ & $<.001$ \\
\hline Male, \% & 45.5 & 45.6 & 45.7 & 45.4 & 0.978 \\
\hline White, \% & 42.9 & 42.7 & 42.4 & 42.8 & 0.963 \\
\hline Black, \% & 38.8 & 38.7 & 38.4 & 38.8 & 0.972 \\
\hline Hispanic, \% & 16.4 & 16.4 & 16.7 & 16.2 & 0.976 \\
\hline \multicolumn{6}{|l|}{ Vitals } \\
\hline Systolic BP, mmHg & $120.2(112.3,133.3)$ & $124.7(116.3,135.0)$ & $126.7(118.0,140.0)$ & $131.0(123.0,139.7)$ & $<.001$ \\
\hline MVPA, min/day & $53.5(41.1)$ & $44.4(35.9)$ & $38.2(31.3)$ & $34.6(28.8)$ & $<.001$ \\
\hline \multicolumn{6}{|l|}{ Anthropometric measures } \\
\hline Body mass index, $\mathrm{kg} / \mathrm{m}^{2}$ & $23.9(21.5,26.0)$ & $27.6(25.1,30.1)$ & $29.7(27.5,32.4)$ & $33.8(31.0,37.3)$ & $<.001$ \\
\hline Waist circumference, $\mathrm{cm}$ & $81.3(74.9,87.0)$ & $88.9(83.8,95.3)$ & $96.5(90.2,101.6)$ & $106.1(100.3,111.8)$ & $<.001$ \\
\hline \multicolumn{6}{|l|}{ Medical history } \\
\hline Hypertension, \% & 24.6 & 28.8 & 43.5 & 57.6 & $<.001$ \\
\hline Diabetes mellitus, \% & 34.7 & 40.9 & 38.0 & 50.6 & 0.001 \\
\hline Hypercholesterolemia, \% & 13.9 & 27.8 & 25.9 & 31.2 & $<.001$ \\
\hline Smoking status, $\%$ & 25.7 & 21.6 & 15.5 & 15.8 & 0.001 \\
\hline \multicolumn{6}{|l|}{ Laboratory data } \\
\hline $\mathrm{LDL}, \mathrm{mg} / \mathrm{dL}$ & $111.0(92.0,135.0)$ & $120.0(95.0,145.0)$ & $119.0(100.0,143.0)$ & $116.0(93.0,142.0)$ & 0.259 \\
\hline $\mathrm{A} 1 \mathrm{C}, \%$ & $5.3(5.1,5.5)$ & $5.4(5.1,5.6)$ & $5.5(5.2,5.7)$ & $5.6(5.3,5.9)$ & $<.001$ \\
\hline $\begin{array}{l}\text { Estimated peak oxygen uptake } \\
\qquad\left(\mathrm{VO}_{2 \mathrm{max}}\right), \mathrm{ml} / \mathrm{kg} / \mathrm{min}\end{array}$ & $32.9(25.7,39.5)$ & $28.4(21.6,33.8)$ & $26.8(21.8,34.0)$ & $23.9(18.9,29.1)$ & $<.001$ \\
\hline \multicolumn{6}{|l|}{ Body composition } \\
\hline Total lean body mass, kg & $38.3(82.2)$ & $40.4(86.7)$ & $42.6(91.9)$ & $45.4(86.2)$ & $<.001$ \\
\hline ALM, $\mathrm{kg}$ & $21.5(5.5)$ & $22.2(5.8)$ & $23.5(6.1)$ & $24.7(5.3)$ & $<.001$ \\
\hline ALM index, $\mathrm{kg} / \mathrm{m}^{2}$ & $7.4(1.4)$ & $7.7(1.5)$ & $8.1(1.5)$ & $8.6(1.28)$ & $<.001$ \\
\hline \multicolumn{6}{|l|}{ CMR measures } \\
\hline LV mass index, $\mathrm{g} / \mathrm{m}^{2}$ & $63.1(54.1,74.4)$ & $58.9(50.0,71.9)$ & $62.1(51.8,71.3)$ & $61.6(54.4,71.6)$ & 0.632 \\
\hline LVEDV index, $\mathrm{mL} / \mathrm{m}^{2}$ & $64.7(56.8,71.3)$ & $58.0(51.8,66.3)$ & $57.5(50.8,63.8)$ & $55.2(49.1,61.9)$ & $<.001$ \\
\hline LVEF, \% & $68.3(64.1,72.9)$ & $69.4(65.3,73.4)$ & $69.1(65.0,73.1)$ & $69.6(65.6,73.6)$ & 0.043 \\
\hline Stroke volume, $\mathrm{mL}$ & $78.5(68.8,89.8)$ & $76.5(67.2,87.4)$ & $78.4(68.4,88.6)$ & $80.1(70.8,89.2)$ & 0.171 \\
\hline Peak systolic circumferential strain, (\%) & $-15.2(-17.1,-13.4)$ & $-14.8(-16.1,-13.2)$ & $-14.3(-16.3,-12.3)$ & $-14.3(-16.1,-12.4)$ & $<.001$ \\
\hline
\end{tabular}

Variables expressed in \%, median with interquartile range, or mean with standard deviation. BP blood pressure, MVPA moderate to vigorous physical activity, LDL lowdensity lipoprotein, ALM appendicular lean mass, CMR cardiovascular magnetic resonance, LVEF left ventricular ejection fraction, LVEDV left ventricular end diastolic volume

cubic splines are shown in Fig. 1. In adjusted analysis, higher amount of VAT was significantly associated with higher $\mathrm{E}_{\mathrm{cc}}$ suggesting greater impairment in LV strain after adjustment for traditional CVD risk factors ( $\beta$ : 0.13, $\mathrm{P}=0.002$; Table 2, Model 1 ). The association remained significant after further adjustment for CRF ( $\beta$ : 0.09, $P=0.042$; Table 2, Model 2), LV parameters ( $\beta$ : $0.15, \mathrm{P}=0.001$; Table 2, Model 3), and other fat depots ( $\beta$ : $0.19, P=0.002$; Table 2, Model 4). Among other regional body fat depots, SAT was not associated with $\mathrm{E}_{\mathrm{cc}}$ in adjusted analysis. Higher LBF was associated with lower $E_{c c}$ suggesting more favorable LV contractility after adjustment for CVD risk factors, CRF, and LV parameters $(\beta:-0.12, P=0.005$; Table 2 , Model $3)$. However, this association was not significant after adjusting for VAT and SAT $(\beta:-0.18, \mathrm{P}=0.054$; Table 2 , Model 4). In sensitivity analysis replacing total lean mass with ALM or ALM index in the most adjusted model, the associations of VAT, SAT and LBF with $\mathrm{E}_{\mathrm{cc}}$ were consistent with that observed in the primary analysis (Additional file 1: Table S1). Furthermore, additional adjustment for MVPA did not modify the 


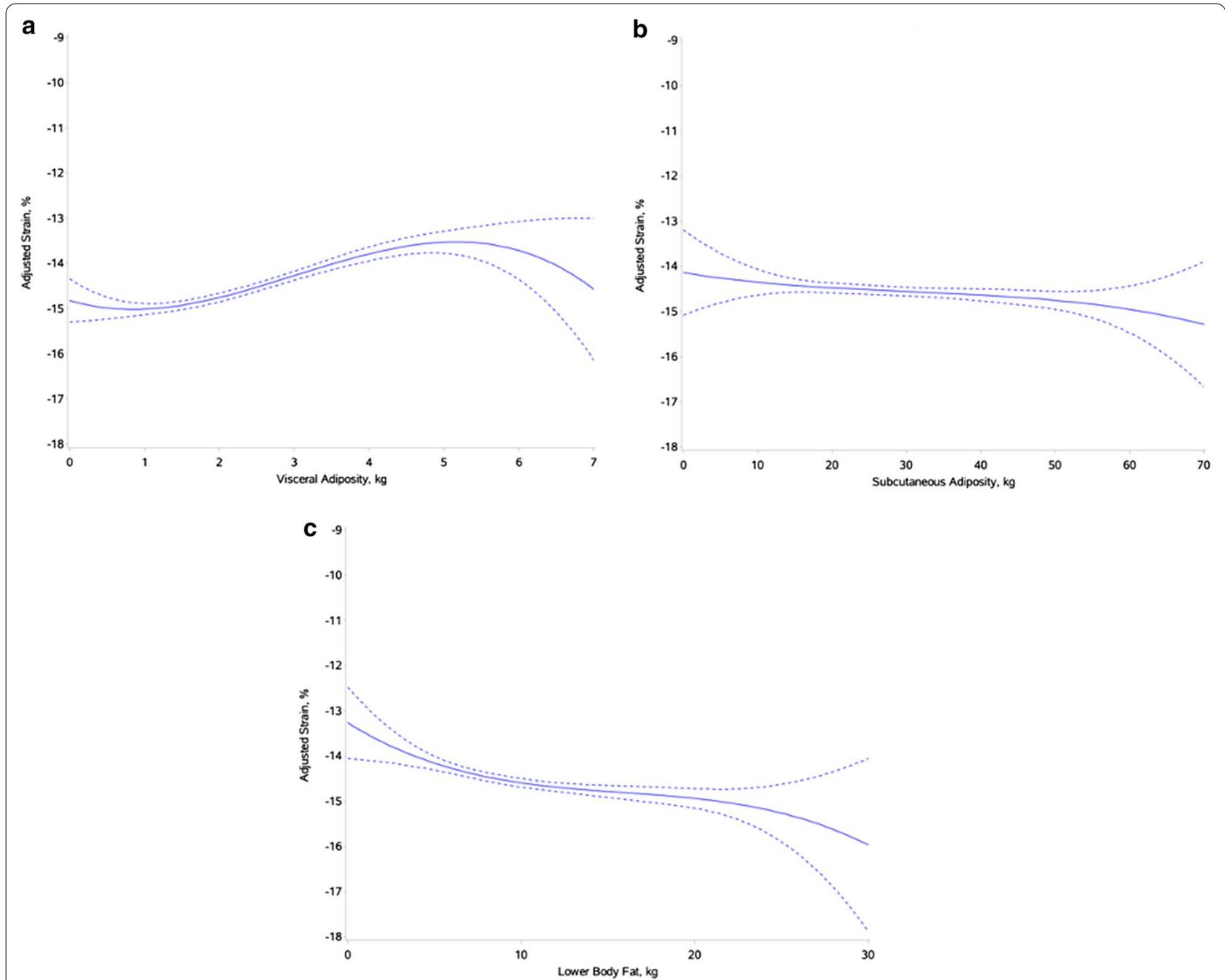

Fig. 1 Restricted cubic splines of visceral adiposity (a), subcutaneous adiposity (b), and lower-body fat (c), and adjusted peak circumferential strain. Each model adjusts for cardiovascular disease (CVD) risk factors, cardiorespiratory fitness (CRF), and left ventricular (LV) parameters (LV mass, LV ejection fraction (LVEF)

Table 2 Multivariable-adjusted associations between VAT, SAT, and LBF with left ventricular peak systolic strain

\begin{tabular}{|c|c|c|c|c|c|c|c|c|}
\hline & \multicolumn{2}{|l|}{ Model 1} & \multicolumn{2}{|l|}{ Model 2} & \multicolumn{2}{|l|}{ Model 3} & \multicolumn{2}{|l|}{ Model 4} \\
\hline & Std. beta & P-value & Std. beta & P-value & Std. beta & P-value & Std. beta & P-value \\
\hline VAT & 0.13 & 0.002 & 0.09 & 0.042 & 0.15 & 0.001 & 0.19 & 0.002 \\
\hline SAT & -0.04 & 0.412 & -0.11 & 0.02 & -0.03 & 0.455 & 0.01 & 0.912 \\
\hline LBF & -0.11 & 0.011 & -0.17 & 0.001 & -0.12 & 0.005 & -0.18 & 0.054 \\
\hline
\end{tabular}

Separate multivariable adjusted linear regression models for VAT, SAT, LBF (independent variables) respectively, and Ecc (dependent variable). Model 1 adjusts for CVD risk factors including age, sex, race, smoking, fasting glucose, diabetes status, hypertension status, systolic blood pressure, and lean body mass. Model 2 adjusts for CVD risk factors and CRF. Model 3 adjusts for CVD risk factors, CRF, and LV parameters (LV mass, LVEF). Model 4 adjusts for CVD risk factors, CRF, and LV parameters (LV mass, LVEF), and includes VAT, SAT, and LBF in the same model. Standardized beta estimate represents change in the outcome of interest per 1-SD increase in the primary exposure variable keeping other covariates fixed. VAT visceral adipose tissue, SAT subcutaneous adipose tissue, LBF lower-body fat, peak systolic circumferential strain (Ecc), left ventricular systolic strain, CVD cardiovascular disease, CRF cardiorespiratory fitness, LV left ventricular, EF ejection fraction 
observed associations of VAT, SAT, and LBF with $\mathrm{E}_{\mathrm{cc}}$ (Additional file 1: Table S1).

In stratified analysis across BMI based subgroups (obese vs. non-obese), the association between higher amount of VAT and impairment in $\mathrm{E}_{\mathrm{cc}}$ was stronger in non-obese vs. obese participants. In contrast, the association between higher amounts of LBF and favorable $\mathrm{E}_{\mathrm{cc}}$ was more evident in obese but not in non-obese participants. SAT was not associated with $\mathrm{E}_{\mathrm{cc}}$ in adjusted analysis in both non-obese and obese subgroups (Table 3).

\section{Association of CRF, MVPA, and lean body mass with peak circumferential strain}

Higher CRF was significantly associated with lower $E_{c c}$ suggesting more favorable contractility independent of CVD risk factors, other echo parameters, regional fat depots, and overall lean mass or ALM (Table 4) (Additional file 1: Table S1). In contrast, MVPA was not associated with $\mathrm{E}_{\mathrm{cc}}$ after accounting for other confounders including CRF. Measures of ALM and ALM index were also not associated with $\mathrm{E}_{\mathrm{cc}}$ in the most adjusted model (Table 4).

\section{Discussion}

In this cohort of individuals free of CVD, we made several important observations. First, higher amounts of VAT were associated with greater impairment in LV contractility, as assessed by $E_{c c}$ independent of traditional CVD risk factors, CRF, LV parameters, and other adipose tissue depots. The association between higher amounts of VAT and greater impairment in LV contractility was more prominent among non-obese individuals as compared with obese individuals. Second, higher LBF

Table 3 Multivariable-adjusted associations of VAT, SAT, and LBF with left ventricular peak systolic strain stratified by body mass index

\begin{tabular}{llllll}
\hline & \multicolumn{2}{l}{ Nonobese } & & & \multicolumn{2}{l}{ Obese } \\
\cline { 2 - 3 } \cline { 5 - 6 } & Std. beta & P-value & & Std. beta & P-value \\
\hline VAT & 0.16 & 0.056 & & 0.01 & 0.849 \\
SAT & 0.16 & 0.205 & & -0.10 & 0.377 \\
LBF & -0.16 & 0.117 & & -0.22 & 0.058 \\
\hline
\end{tabular}

Multivariable adjusted linear regression models for VAT, SAT, LBF (independent variables) and Ecc (dependent variable) stratified by BMI. Nonobese defined as $\mathrm{BMI} \leq 30 \mathrm{~m} / \mathrm{kg}^{2}$. Obese defined as $>30 \mathrm{~kg} / \mathrm{m}^{2}$. Model adjusts for age, sex, race, smoking, fasting glucose, diabetes status, hypertension status, systolic blood pressure, lean body mass, CRF, and LV parameters (LV mass, LVEF), and includes VAT, SAT, and LBF in the same model

Standardized beta estimate represents change in the outcome of interest per 1-SD increase in the primary exposure variable keeping other covariates fixed. VAT visceral adipose tissue, SAT subcutaneous adipose tissue, $L B F$ lower-body fat, peak systolic circumferential strain (Ecc), left ventricular systolic strain; $B M I$ body mass index, CVD cardiovascular disease, $C R F$ cardiorespiratory fitness, $L V$ left ventricular, EF ejection fraction
Table 4 Multivariable-adjusted associations between appendicular lean mass, physical activity and left ventricular peak systolic strain

\begin{tabular}{lll}
\hline & Std. beta & P-value \\
\hline ALM $^{a}$ & -0.05 & 0.380 \\
ALM index $^{b}$ & -0.01 & 0.971 \\
MVPA $^{c}$ & 0.01 & 0.897 \\
CRF $^{c}$ & -0.15 & $<.001$ \\
\hline
\end{tabular}

Standardized beta estimate represents change in the outcome of interest per $1-S D$ increase in the primary exposure variable keeping other covariates fixed. ALM appendicular lean mass, CRF cardiorespiratory fitness, MVPA moderate to vigorous physical activity

${ }^{a}$ Multivariable adjusted linear regression model with Ecc as an outcome and following covariates: age, sex, race, smoking, fasting glucose, diabetes status, hypertension status, systolic blood pressure, ALM, CRF, LV mass, LVEF, VAT, SAT, and LBF

${ }^{\mathrm{b}}$ Multivariable adjusted linear regression model with Ecc as an outcome and following covariates: age, sex, race, smoking, fasting glucose, diabetes status, hypertension status, systolic blood pressure, ALM index, CRF, LV mass, LVEF, VAT, SAT, and LBF

${ }^{C}$ Multivariable adjusted linear regression model with Ecc as an outcome and following covariates: age, sex, race, smoking, fasting glucose, diabetes status, hypertension status, systolic blood pressure, total body lean mass index, CRF, LV mass, LVEF, VAT, SAT, LBF, and MVPA

was associated with a trend towards more favorable LV contractility while SAT was not associated with LV contractility. Third, higher CRF was associated with more favorable LV contractility, independent of other risk factors, LV parameters, and regional adipose tissue depots. Finally, total lean body mass as well as ALM were not associated with measures of LV contractility after adjustment for other potential confounders. Our findings highlight the independent contributions of VAT and CRF to LV subclinical systolic dysfunction (Fig. 2), an intermediate phenotype associated with greater risk of HF.

Previous studies have characterized the abnormal cardiac remodeling patterns associated with higher VAT. Specifically, investigators have reported a cross-sectional association between high VAT and increased LV concentricity (higher LV mass, lower LVEDV), independent of CVD risk factors and BMI [5, 8, 9]. In contrast, studies have not demonstrated an independent association between VAT and systolic dysfunction as measured by LVEF [5, 23]. LVEF is a crude measure of LV systolic function and may not be sensitive enough to capture subtle abnormalities in LV contractility in otherwise healthy individuals. Consistent with this notion, prior studies have demonstrated a significant inverse association between VAT and LV contractility as assessed by global longitudinal strain $[24,25]$. However, these studies did not account for differences in other regional adiposity depots and CRF, which may be important confounders in the observed associations. Findings from 


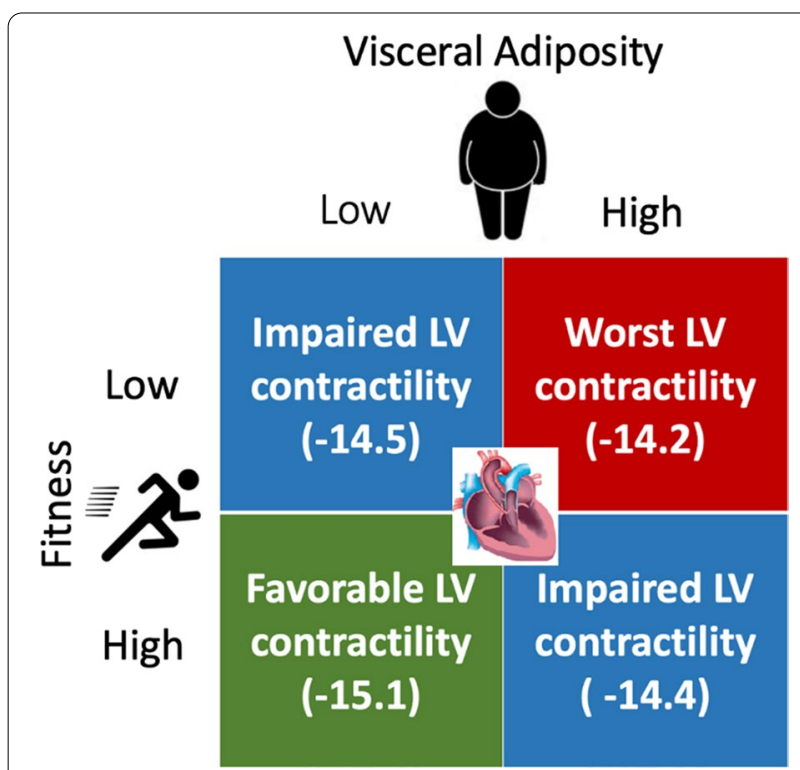

Fig. 2 Association of varying visceral adiposity (VAT) (high/low) and CRF (high/low) levels with LV contractility. The cohort is divided into 4 groups based on high and low CRF and VAT by race and sex specific medians. Mean peak systolic circumferential strain $\left(E_{c c}\right)$ of each group is reported

the present study add to the existing literature demonstrating a significant association between LV strain and abnormalities in LV contractility independent of CRF and other regional adiposity depots.

The location of excess adiposity may influence the cardiac remodeling pattern that occurs in obese individuals. While VAT is implicated in the development of concentric LV remodeling, excess LBF has been more strongly associated with eccentric LV remodeling [9]. In contrast, SAT has not been consistently associated with abnormal LV remodeling in previous studies $[8,9]$. Consistent with prior observations, SAT was not associated with LV contractility in the adjusted models in the present study. However, we observed an association between higher amounts of LBF and more favorable LV contractility. Several factors may underlie the observed association between LBF and favorable LV contractility. Previous studies have demonstrated a significant association between higher LBF and lower burden of cardiovascular risk factors, less concentric remodeling, improved systemic vascular resistance, and lower rate of cardiovascular disease [9, 26, 27]. Also, LBF may contribute to a more favorable cardiometabolic profile by serving as a metabolic sink, absorbing excess circulating lipids thereby protecting other tissues from the harmful downstream consequences of ectopic fat deposition $[28,29]$. Consistent with this notion, we observed a more favorable association between LBF and LV contractility in obese individuals but not in non-obese individuals.

The mechanisms underlying the observed association between higher VAT and worse LV strain are not well established. VAT is epidemiologically linked to CVD risk factors such as hyperlipidemia, hypertension, and diabetes [30, 31], and may lead to abnormal cardiac remodeling and LV contractility through the excess burden of risk factors [5, 32]. Consistently, studies have observed that risk of HF associated with VAT is driven by greater burden of cardiometabolic risk factors [5, 33]. It is noteworthy that a more independent association between VAT and risk of HF has been reported, specifically with HF with preserved LVEF (HFpEF) [12]. Findings from our study suggest that the higher risk of HF, particularly HFpEF, in patients with higher amounts of VAT may be related to impairment in myocardial contractility independent of traditional CVD risk factors. This is particularly relevant since studies have implicated LV strain impairment in the development of HFpEF [34]. We also observed that the association between higher VAT and worse LV contractility was more pronounced among participants in the normal to overweight BMI range. This highlights the potential adverse cardiac effects of higher visceral adiposity in normal to overweight individuals. Consistent with our observation, prior studies have linked higher VAT and central adiposity to adverse cardiometabolic profile, greater arterial stiffness, and greater CVD risk in normal to overweight individuals [35-37]. VAT may mediate myocardial dysfunction through a number of mechanisms. VAT activates macrophages leading to the secretion of cytokines such as interleukin- 6 and tumor necrosis which may potentiate inflammation and fibrosis of the myocardium [38]. Locally, the presence of VAT induces changes in cardiac tissue that lead to myocardial fibrosis, cardiomyocyte hypertrophy, and macrophage infiltration, all of which may contribute to abnormal cardiac remodeling patterns and dysfunction in myocardial contractility.

We observed that higher CRF levels were associated with more favorable LV contractility independent of other risk factors as well as regional adiposity burden. Prior studies have observed an inverse association between CRF and HF risk, independent of CVD risk factor burden and BMI [39-43]. Furthermore, low CRF has been associated with abnormal cardiac remodeling patterns characterized by higher LV filling pressure, diastolic dysfunction, and impairment in $\mathrm{E}_{\mathrm{cc}}[10,11,16]$. It is noteworthy that prior analyses linking CRF to abnormalities in cardiac structure and function and downstream HF risk did not account for differences in regional adiposity burden. The present study suggests the positive 
association between high CRF and favorable cardiac remodeling, may be independent of regional adiposity burden.

Our study findings have important clinical implications. The independent associations of higher VAT and lower CRF with subclinical abnormalities in LV contractility highlight their potential role as modifiable targets for HF prevention [44, 45]. Observational studies of individuals who have undergone bariatric surgery suggest that substantial weight loss can reverse pathological cardiac remodeling and reduce risk of incident $\operatorname{HF}[46$, 47]. More recently, findings from the Look AHEAD trial have demonstrated that greater loss of overall and central adiposity with lifestyle interventions is associated with lower risk of HF [48]. Furthermore, temporal improvement in CRF has been associated with improved systolic and diastolic parameters [11] and lower risk of HF [7]. Despite these promising observations, interventions targeting non-specific weight loss and improvement in CRF have not demonstrably been shown to reduce HF risk $[43,49]$. Future studies are needed to evaluate if preventive strategies aimed at lowering VAT and optimizing CRF can favorably modify LV structure and function and mitigate the downstream risk of HF.

\section{Limitations}

Our study has limitations. First, our study is crosssectional and therefore does not establish a causal relationship between VAT, CRF, and subclinical systolic dysfunction. Second, our study was observational, rendering it susceptible to residual confounding. Third, our findings may not be generalizable to individuals with established CVD, as LV morphology and function may be different compared to our study population. Fourth, there was a lack of data on right ventricular parameters and diastolic function, both of which may represent intermediate phenotypes along the progression to clinical HF $[13,50]$. This precluded inclusion of these parameters into the analysis. Fifth, the present study did not have available data on muscular strength, which is associated with CRF and is implicated in the development and progression of HF [51, 52]. However, we observed no associations between overall lean mass and ALM, with LV contractility. Furthermore, the cross-sectional associations between VAT, CRF and $E_{c c}$ were also independent of total lean mass and ALM. Sixth, DEXA derived estimates of VAT were used in the present analysis, as magnetic resonance imaging, a superior modality for quantifying VAT, was not available. Seventh, there was moderate degree of variability in our $E_{c c}$ measures based on correlation and Bland Altman plot statistics highlighting the need for validation of the observed results in other cohorts. Finally, due to a limited number of incident HF events in the DHS cohort, the longitudinal associations between $\mathrm{E}_{\mathrm{cc}}$ and regional adiposity with incident HF could not be assessed.

In conclusion, in a multiethnic cohort of adults without CVD, higher amounts of VAT were associated with myocardial dysfunction as measured by $\mathrm{E}_{\mathrm{cc}}$ independent of traditional CVD risk factors, other echocardiographic parameters, and CRF. Furthermore, lower CRF was associated with impairment in $\mathrm{E}_{\mathrm{cc}}$ independent of CVD risk factors and regional adiposity burden. These findings suggest VAT and CRF may mediate pathological cardiac remodeling through distinct processes. More studies are needed to investigate VAT and CRF as potential targets for HF prevention, and elucidate the interplay between VAT, CRF, and BMI in the development of HF.

\section{Abbreviations}

ALM: Appendicular lean mass; BMI: Body mass index; CMR: Cardiovascular magnetic resonance; CRF: Cardiorespiratory fitness; CVD: Cardiovascular disease; DEXA: Dual-energy X-ray absorptiometry; DHS: Dallas Heart Study; E Peak systolic circumferential strain; ECG: Electrocardiogram; EDV: End-diastolic volume; HF: Heart failure; HFpEF: Heart failure with preserved ejection fraction; LBF: Lower-body fat; LV: Left ventricle/left ventricular; LVEDV: Left ventricular end-diastolic volume; LVEF: Left ventricular ejection fraction; LVESV: Left ventricular end-systolic volume; MVPA: Moderate to vigorous physical activity; VAT: Visceral adiposity; $\mathrm{VO}_{2}$ : Oxygen uptake; $\mathrm{VO}_{2 \text { max }}$ : Peak oxygen uptake.

\section{Supplementary Information}

The online version contains supplementary material available at https://doi. org/10.1186/s12968-021-00757-w.

Additional file 1: Table S1. Multivariable-Adjusted Associations between VAT, SAT, and LBF with Left Ventricular Peak Systolic Strain, with Adjustment for ALM and ALM index. Figure S1. Bland-Altman Plot (A) and Line Regression (B) of Peak Circumferential Strain Measurements. The Bland Altman plot displays the mean difference between the 2 measurements for each participant plotted on the $Y$ axis. The mean of the 2 measurements is plotted on the $X$ axis. The linear regression displays the first strain measurement on the $X$-axis and the second strain measurement on the $Y$-axis.

\section{Acknowledgements}

We acknowledge all participants and investigators of the Dallas heart study.

\section{Authors' contributions}

AP conceived of study plan and supervised the project. CA conducted the statistical analysis. NK contributed to analysis plan, interpreted study findings, and wrote the manuscript. NT, KVP, AC, JDB, and IJN provided critical feedback and helped shape the research, analysis, and manuscript. All authors read and approved the final manuscript.

\section{Funding}

Dr. Pandey has received research support from Texas Health Resources Clinical Scholarship, the Gilead Sciences Research Scholar Program, the National Institute of Aging GEMSSTAR Grant (1R03AG067960-01), and Applied Therapeutics. Dr. Neeland is supported by the National Institutes of Health K23DK106520 grant. Dr. Kondamudi is supported by the National Institutes of Health 2T32HL125247-06. The Dallas Heart Study was funded by the Donald W. Reynolds Foundation and was partially supported by the National Center for Advancing Translational Sciences of the National Institutes of Health under award number UL1TR001105. 


\section{Availability of data and materials}

The data that support the findings of this study are available in the Dallas Heart Study Cohort. The data is not publicly available; however, it can be made available from the authors upon request to the Dallas Heart Study Cohort panel.

\section{Declarations}

\section{Ethics approval and consent to participate}

All participants provided written informed consent. The institutional review board of the University of Texas Southwestern Medical Center approved the study.

\section{Consent for publication}

Not applicable.

\section{Competing interests}

Dr. Pandey has served on the advisory board of Roche Diagnostics. Dr. Neeland reports being an investigator on a trial of liraglutide (Novo Nordisk) for obesity and being a former speaker/consultant for Boehringer Ingelheim/Lilly Alliance. Colby Ayers reported personal fees from the National Institutes of Health outside the submitted work.

\section{Author details}

${ }^{1}$ Division of Cardiology, Department of Internal Medicine, University of Texas Southwestern Medical Center, 5323 Harry Hines Blvd, Dallas, TX 75390-9047, USA. ${ }^{2}$ Department of Clinical Sciences, University of Texas Southwestern Medical Center, 5323 Harry Hines Blvd, Dallas, TX 75390-9047, USA. ${ }^{3}$ Division of Cardiology, Department of Internal Medicine, Northwestern University, Feinberg School of Medicine, Chicago, IL 60611, USA. ${ }^{4}$ Division of Cardiology, Department of Internal Medicine, Houston Methodist Hospital, 6550 Fannin St., Houston, TX 77030, USA. ${ }^{5}$ Division of Cardiology, Department of Internal Medicine, University Hospitals Harrington Heart and Vascular Institute and Case Western Reserve University School of Medicine, 2103 Cornell Road, Cleveland, $\mathrm{OH}$ 44106, USA.

Received: 9 November 2020 Accepted: 6 April 2021

Published online: 14 June 2021

\section{References}

1. Lauer MS, Anderson KM, Kannel WB, Levy D. The impact of obesity on left ventricular mass and geometry. The Framingham Heart Study. JAMA. 1991;266:231-6.

2. Kenchaiah S, Evans JC, Levy D, Wilson PW, Benjamin EJ, Larson MG, Kannel WB, Vasan RS. Obesity and the risk of heart failure. N Engl J Med. 2002;347:305-13.

3. Kenchaiah S, Gaziano JM, Vasan RS. Impact of obesity on the risk of heart failure and survival after the onset of heart failure. Med Clin North Am. 2004;88:1273-94.

4. Aune D, Sen A, Norat T, Janszky I, Romundstad P, Tonstad S, Vatten LJ. Body mass index, abdominal fatness, and heart failure incidence and mortality: a systematic review and dose-response meta-analysis of prospective studies. Circulation. 2016;133:639-49.

5. Pandey A, Kondamudi N, Patel KV, Ayers C, Simek S, Hall ME, Musani SK, Blackshear C, Mentz RJ, Khan H, Terry JG, Correa A, Butler J, Neeland IJ, Berry JD. Association between regional adipose tissue distribution and risk of heart failure among blacks. Circ Heart Fail. 2018;11:e005629.

6. Pandey A, LaMonte M, Klein L, Ayers C, Psaty BM, Eaton CB, Allen NB, de Lemos JA, Carnethon M, Greenland P, Berry JD. Relationship between physical activity, body mass index, and risk of heart failure. J Am Coll Cardiol. 2017;69:1129-42.

7. Pandey A, Patel M, Gao A, Willis BL, Das SR, Leonard D, Drazner MH, de Lemos JA, DeFina L, Berry JD. Changes in mid-life fitness predicts heart failure risk at a later age independent of interval development of cardiac and noncardiac risk factors: the Cooper Center Longitudinal Study. Am Heart J. 2015:169:290-297 e291.

8. Abbasi SA, Hundley WG, Bluemke DA, Jerosch-Herold M, Blankstein R, Petersen SE, Rider OJ, Lima JA, Allison MA, Murthy VL, Shah RV. Visceral adiposity and left ventricular remodeling: the multi-ethnic study of atherosclerosis. Nutr Metab Cardiovasc Dis. 2015;25:667-76.

9. Neeland IJ, Gupta S, Ayers CR, Turer AT, Rame JE, Das SR, Berry JD, Khera A, McGuire DK, Vega GL, Grundy SM, de Lemos JA, Drazner MH. Relation of regional fat distribution to left ventricular structure and function. Circ Cardiovasc Imaging. 2013;6:800-7.

10. Brinker SK, Pandey A, Ayers CR, Barlow CE, DeFina LF, Willis BL, Radford NB, Farzaneh-Far R, de Lemos JA, Drazner MH, Berry JD. Association of cardiorespiratory fitness with left ventricular remodeling and diastolic function: the Cooper Center Longitudinal Study. JACC Heart Fail. 2014;2:238-46.

11. Pandey A, Allen N, Ayers C, Reis J, Moreira H, Sidney S, Rana J, Jacobs D, Chow L, Lemos J, Carnethon M, Berry J. Fitness in young adulthood and long-term cardiac structure and function. The CARDIA Study. JACC Heart Fail. 2017;5:347-55.

12. Rao VN, Zhao D, Allison MA, Guallar E, Sharma K, Criqui MH, Cushman M, Blumenthal RS, Michos ED. Adiposity and incident heart failure and its subtypes: MESA (multi-ethnic study of atherosclerosis). JACC Heart Fail. 2018;6:999-1007.

13. Zile M, Baicu C, Gaasch W. Diastolic heart failure-abnormalities in active relaxation and passive stiffness of the left ventricle. $\mathrm{N}$ Engl J Med. 2004;350:1953-9.

14. Cho GY, Marwick TH, Kim HS, Kim MK, Hong KS, Oh DJ. Global 2-dimensional strain as a new prognosticator in patients with heart failure. J Am Coll Cardiol. 2009;54:618-24.

15. Choi EY, Rosen BD, Fernandes VR, Yan RT, Yoneyama K, Donekal S, Opdahl A, Almeida AL, Wu CO, Gomes AS, Bluemke DA, Lima JA. Prognostic value of myocardial circumferential strain for incident heart failure and cardiovascular events in asymptomatic individuals: the Multi-Ethnic Study of Atherosclerosis. Eur Heart J. 2013;34:2354-61.

16. Pandey A, Park B, Martens S, Ayers C, Neeland IJ, Haykowsky MJ, Nelson MD, Sarma S, Berry JD. Relationship of cardiorespiratory fitness and adiposity with left ventricular strain in middle-age adults (from the Dallas Heart Study). Am J Cardiol. 2017;120:1405-9.

17. Victor RG, Haley RW, Willett DL, Peshock RM, Vaeth PC, Leonard D, Basit M, Cooper RS, lannacchione VG, Visscher WA, Staab JM, Hobbs HH, Dallas Heart Study. The Dallas Heart Study: a population-based probability sample for the multidisciplinary study of ethnic differences in cardiovascular health. Am J Cardiol. 2004;93:1473-80.

18. Pandey A, Park BD, Ayers C, Das SR, Lakoski S, Matulevicius S, de Lemos $J A$, Berry JD. Determinants of racial/ethnic differences in cardiorespiratory fitness (from the Dallas Heart Study). Am J Cardiol. 2016;118:499-503.

19. Lakoski SG, Kozlitina J. Ethnic differences in physical activity and metabolic risk: the Dallas Heart Study. Med Sci Sports Exerc. 2014;46:1124-32.

20. Chung AK, Das SR, Leonard D, Peshock RM, Kazi F, Abdullah SM, Canham RM, Levine BD, Drazner MH. Women have higher left ventricular ejection fractions than men independent of differences in left ventricular volume: the Dallas Heart Study. Circulation. 2006;113:1597-604.

21. Osman NF, Prince JL. Visualizing myocardial function using HARP MRI. Phys Med Biol. 2000;45:1665-82.

22. Garot J, Bluemke DA, Osman NF, Rochitte CE, McVeigh ER, Zerhouni EA, Prince JL, Lima JA. Fast determination of regional myocardial strain fields from tagged cardiac images using harmonic phase MRI. Circulation. 2000;101:981-8.

23. Fontes-Carvalho R, Fontes-Oliveira M, Sampaio F, Mancio J, Bettencourt N, Teixeira M, Rocha Goncalves F, Gama V, Leite-Moreira A. Influence of epicardial and visceral fat on left ventricular diastolic and systolic functions in patients after myocardial infarction. Am J Cardiol. 2014;114:1663-9.

24. Van Berendoncks AM, Van Gaal L, De Block C, Buys D, Salgado R, Vrints C, Shivalkar B. Abnormal longitudinal peak systolic strain in asymptomatic patients with type I diabetes mellitus. Echocardiography. 2019;36:478-85.

25. Sawada N, Nakanishi K, Daimon M, Yoshida Y, Ishiwata J, Hirokawa M, Nakao T, Morita H, Di Tullio MR, Homma S, Komuro I. Influence of visceral adiposity accumulation on adverse left and right ventricular mechanics in the community. Eur J Prev Cardiol. 2019. https://doi.org/10.1177/20474 87319891286.

26. Neeland IJ, Turer AT, Ayers CR, Berry JD, Rohatgi A, Das SR, Khera A, Vega GL, MCGuire DK, Grundy SM, de Lemos JA. Body fat distribution and incident cardiovascular disease in obese adults. J Am Coll Cardiol. 2015:65:2150-1. 
27. Manolopoulos KN, Karpe F, Frayn KN. Gluteofemoral body fat as a determinant of metabolic health. Int J Obes (Lond). 2010;34:949-59.

28. Neeland IJ, Poirier P, Despres JP. Cardiovascular and metabolic heterogeneity of obesity: clinical challenges and implications for management. Circulation. 2018;137:1391-406.

29. Murase T, Hattori T, Ohtake M, Abe M, Amakusa Y, Takatsu M, Murohara T, Nagata K. Cardiac remodeling and diastolic dysfunction in DahIS.ZLepr(fa)/Lepr(fa) rats: a new animal model of metabolic syndrome. Hypertens Res. 2012;35:186-93.

30. Fox CS, Massaro JM, Hoffmann U, Pou KM, Maurovich-Horvat P, Liu CY, Vasan RS, Murabito JM, Meigs JB, Cupples LA, D'Agostino RB Sr, O'Donnell CJ. Abdominal visceral and subcutaneous adipose tissue compartments: association with metabolic risk factors in the Framingham Heart Study. Circulation. 2007;1 16:39-48.

31. Neeland IJ, Turer AT, Ayers CR, Powell-Wiley TM, Vega GL, Farzaneh-Far R, Grundy SM, Khera A, McGuire DK, de Lemos JA. Dysfunctional adiposity and the risk of prediabetes and type 2 diabetes in obese adults. JAMA. 2012;308:1150-9.

32. Vega GL, Adams-Huet B, Peshock R, Willett D, Shah B, Grundy SM. Influence of body fat content and distribution on variation in metabolic risk. J Clin Endocrinol Metab. 2006;91:4459-66.

33. Nicklas BJ, Cesari M, Penninx BW, Kritchevsky SB, Ding J, Newman A, Kitzman DW, Kanaya AM, Pahor M, Harris TB. Abdominal obesity is an independent risk factor for chronic heart failure in older people. J Am Geriatr Soc. 2006:54:413-20.

34. DeVore AD, McNulty S, Alenezi F, Ersboll M, Vader JM, Oh JK, Lin G, Redfield MM, Lewis G, Semigran MJ, Anstrom KJ, Hernandez AF, Velazquez EJ. Impaired left ventricular global longitudinal strain in patients with heart failure with preserved ejection fraction: insights from the RELAX trial. Eur J Heart Fail. 2017;19:893-900.

35. Bouchi R, Minami I, Ohara N, Nakano Y, Nishitani R, Murakami M, Takeuchi T, Akihisa M, Fukuda T, Fujita M, Yoshimoto T, Ogawa Y. Impact of increased visceral adiposity with normal weight on the progression of arterial stiffness in Japanese patients with type 2 diabetes. BMJ Open Diabetes Res Care. 2015:3:e000081.

36. Katsuki A, Sumida Y, Urakawa H, Gabazza EC, Murashima S, Maruyama N, Morioka K, Nakatani K, Yano Y, Adachi Y. Increased visceral fat and serum levels of triglyceride are associated with insulin resistance in Japanese metabolically obese, normal weight subjects with normal glucose tolerance. Diabetes Care. 2003;26:2341-4

37. Sahakyan KR, Somers VK, Rodriguez-Escudero JP, Hodge DO, Carter RE, Sochor O, Coutinho T, Jensen MD, Roger VL, Singh P, Lopez-Jimenez F. Normal-weight central obesity: implications for total and cardiovascular mortality. Ann Intern Med. 2015;163:827-35.

38. Ouchi N, Parker JL, Lugus JJ, Walsh K. Adipokines in inflammation and metabolic disease. Nat Rev Immunol. 2011;11:85-97.

39. Berry JD, Pandey A, Gao A, Leonard D, Farzaneh-Far R, Ayers C, DeFina $L$, Willis $B$. Physical fitness and risk for heart failure and coronary artery disease. Circ Heart Fail. 2013;6:627-34.

40. Khan H, Kunutsor S, Rauramaa R, Savonen K, Kalogeropoulos AP, Georgiopoulou W, Butler J, Laukkanen JA. Cardiorespiratory fitness and risk of heart failure: a population-based follow-up study. Eur J Heart Fail. 2014;16:180-8

41. Kupsky DF, Ahmed AM, Sakr S, Qureshi WT, Brawner CA, Blaha MJ, Ehrman JK, Keteyian SJ, Al-Mallah MH. Cardiorespiratory fitness and incident heart failure: The Henry Ford Exerclse Testing (FIT) Project. Am Heart J. 2017; 185:35-42.

42. Kokkinos P, Faselis C, Franklin B, Lavie CJ, Sidossis L, Moore H, Karasik P, Myers J. Cardiorespiratory fitness, body mass index and heart failure incidence. Eur J Heart Fail. 2019;21:436-44.

43. Pandey A, Patel KV, Bahnson JL, Gaussoin SA, Martin CK, Balasubramanyam A, Johnson KC, McGuire DK, Bertoni AG, Kitzman D, Berry JD, Look ARG. Association of intensive lifestyle intervention, fitness, and body mass index with risk of heart failure in overweight or obese adults with type 2 diabetes mellitus: an analysis from the Look AHEAD Trial. Circulation. 2020;141:1295-306

44. Elagizi A, Carbone S, Lavie CJ, Mehra MR, Ventura HO. Implications of obesity across the heart failure continuum. Prog Cardiovasc Dis. 2020;63:561-9.

45. Neeland IJ, Yokoo T, Leinhard OD, Lavie Carl J. 21st century advances in multimodality imaging of obesity for care of the cardiovascular patient JACC Cardiovasc Imaging. 2021;14(2):482-94.

46. Lascaris B, Pouwels S, Houthuizen P, Dekker LR, Nienhuijs SW, Bouwman RA, Buise MP. Cardiac structure and function before and after bariatric surgery: a clinical overview. Clin Obes. 2018;8:434-43.

47. Sundstrom J, Bruze G, Ottosson J, Marcus C, Naslund I, Neovius M. Weight loss and heart failure: a nationwide study of gastric bypass surgery versus intensive lifestyle treatment. Circulation. 2017;135:1577-85.

48. Patel KV, Bahnson JL, Gaussoin SA, Johnson KC, Pi-Sunyer X, White U, Olson KL, Bertoni AG, Kitzman DW, Berry JD, Pandey A, Look ARG. Association of baseline and longitudinal changes in body composition measures with risk of heart failure and myocardial infarction in type 2 diabetes: findings from the Look AHEAD Trial. Circulation. 2020;142:2420-30.

49. Look ARG, Wing RR, Bolin P, Brancati FL, Bray GA, Clark JM, Coday M, Crow RS, Curtis JM, Egan CM, Espeland MA, Evans M, Foreyt JP, Ghazarian S, Gregg EW, Harrison B, Hazuda HP, Hill JO, Horton ES, Hubbard VS, Jakicic JM, Jeffery RW, Johnson KC, Kahn SE, Kitabchi AE, Knowler WC, Lewis CE, Maschak-Carey BJ, Montez MG, Murillo A, Nathan DM, Patricio J, Peters A, Pi-Sunyer X, Pownall H, Reboussin D, Regensteiner JG, Rickman AD, Ryan DH, Safford M, Wadden TA, Wagenknecht LE, West DS, Williamson DF, Yanovski SZ. Cardiovascular effects of intensive lifestyle intervention in type 2 diabetes. N Engl J Med. 2013;369:145-54.

50. Nochioka K, Querejeta Roca G, Claggett B, Biering-Sorensen T, Matsushita K, Hung CL, Solomon SD, Kitzman D, Shah AM. Right ventricular function, right ventricular-pulmonary artery coupling, and heart failure risk in 4 US communities: the Atherosclerosis Risk in Communities (ARIC) Study. JAMA Cardiol. 2018:3:939-48.

51. Carbone S, Billingsley HE, Rodriguez-Miguelez P, Kirkman DL, Garten R, Franco RL, Lee D-C, Lavie CJ. Lean mass abnormalities in heart failure: the role of sarcopenia sarcopenic obesity, and cachexia. Curr Probl Cardiol. 2020:45:100417.

52. Carbone S, Kirkman DL, Garten RS, Rodriguez-Miguelez P, Artero EG, Lee D-C, et al. Muscular strength and cardiovascular disease: AN UPDATED STATE-OF-THE-ART NARRATIVE REVIEW. J Cardiopulm Rehabil Prevent. 2020;40(5):302-9.

\section{Publisher's Note}

Springer Nature remains neutral with regard to jurisdictional claims in published maps and institutional affiliations. 